\title{
TEACHING INDUSTRY 4.0
}

\author{
Gilberto Marzano \\ Rezekne Academy of Technologies, Rezekne, Latvia \\ Spoleczna Akademia Nauk, Łódź, Poland \\ Andris Martinovs \\ Rezekne Academy of Technologies, Rezekne, Latvia
}

\begin{abstract}
Industry 4.0 is a term that was introduced by the German government at the time of the Hannover Fair in 2011 in relation to an initiative brought forward to support German industry in addressing future challenges. It refers to the 4th industrial revolution, in which disruptive digital technologies, such as the Internet of Things (IoT), robotics, virtual reality (VR), and artificial intelligence (AI), are exercising a notable impact on industrial production. Industry 4.0 takes the emphasis on digital technology of recent decades to a whole new level with the help of interconnectivity through the Internet of Things (IoT), real-time data access, and the introduction of cyber-physical systems.

This paper focuses on the design of an educational module for higher education mechatronics students. Introducing Industry 4.0 into a mechatronics curriculum will reinforce the integration of student competences in flexible and rapid manufacturing. The module includes notions of machine learning and deep machine learning, which are essential in robotics and behavioral robotics and closely interact with control theory. The results of a pilot training activity in the field are also illustrated and discussed.
\end{abstract}

Keyword: industry 4.0, mechatronics curriculum, mechatronics education, machine learning, smart factories.

\section{Introduction}

It is broadly accepted that human society has, to date, passed through four distinct industrial revolutions, which can be individuated as follows:

1. The First Industrial Revolution - that occurred between the late 1700s and early 1800s. The key characteristics of this revolution were the use of water and steam-powered machines, and the introduction of more optimized forms of working.

2. The Second Industrial Revolution - in the early part of the 20th century, was characterized by the introduction of steel and the use of electricity in factories. During this phase, concepts of mass production such as the assembly line were introduced as a way of boosting productive output. 
3. The Third Industrial Revolution - slowly began to emerge in the late 1950s as manufacturers began incorporating more and more electronic and digital technology into their factories.

4. The Fourth Industrial Revolution, or Industry 4.0 - that has come about over the last few decades, is based on the integrated use of digital technology and new levels of interconnectivity through the Internet of Things (IoT), allowing real-time access to data and the introduction of cyber-physical systems.

Industry 4.0, more specifically, is a term introduced by the German government at the Hannover Fair in 2011 in relation to an initiative it brought forward to support German industry to address future challenges (Qin, Liu, \& Grosvenor, 2016). It refers to the 4th industrial revolution in which disruptive digital technologies, such as the Internet of Things (IoT), robotics, virtual reality (VR), and artificial intelligence (AI), are having an impact on industrial production (Lasi, Fettke, Kemper, Feld, \& Hoffmann, 2014).

Over the last few years, the term Industry 4.0 has become an often-quoted buzzword, used fairly indiscriminately to describe digitalization in any phase of the value chain of an enterprise (Herman, Pentek, \& Otto, 2016). Indeed, it encompasses the full range of activities that an enterprise must instigate in order to create a product or service (European Commission, 2018). It is primarily focused on how production shop floors operate at the current time, but also involves elements of procurement and supply management (Glas \& Kleemann, 2016).

\section{Basic concepts of Industry 4.0}

M2M (machine-to-machine), big data, AI, and IoT are all characterizing elements of Industry 4.0. In an Industry 4.0 environment, smart machines communicate with each other, manage the production lines, and analyze and solve production issues with minimal human involvement. Amazon warehouses, based on advanced automation solutions and IoT applications, represent one of the most notable examples of Industry 4.0. In an Amazon warehouse, when an order is generated, machines immediately check the availability of the ordered item. If the item is in stock, it is instantly prepared for shipping. The IoT supports this process.

The basic concepts of Industry 4.0 can be outlined, in a non-exhaustive way, as follows:

- Enterprise Resource Planning (ERP): encompasses business process management tools used to manage information across an organization;

- IoT: an abbreviation for the Internet of Things, is a concept that refers to connections between physical objects such as sensors or machines and the Internet; 
- IIoT: that stands for the Industrial Internet of Things, is a concept that refers to the connections between people, data, and machines as it relates to manufacturing;

- Big data: refers to large sets of structured or unstructured data that can be compiled, stored, organized, and analyzed in order to reveal patterns, trends, associations, and opportunities;

- Artificial intelligence (AI): refers to a computer's ability to perform tasks and make decisions that would ordinarily require some degree of human intelligence;

- M2M: stands for machine-to-machine, and refers to the communication that occurs between two individual machines through wireless or wired networks;

- Digitization: that refers to the process of collecting and converting different types of information into a digital format;

- Smart factory: a smart factory is one that invests in and leverages Industry 4.0 technology, solutions, and approaches;

- Machine learning: refers to the ability that computers have to learn and improve on their own through artificial intelligence, without being explicitly told or programmed to do so;

- Cloud computing: refers to the practice of using interconnected remote servers hosted on the Internet to store, manage, and process information;

- Real-time data processing: refers to the abilities of computer systems and machines to continuously and automatically process data and provide real-time or near-time outputs and insights;

- Ecosystem: in manufacturing terms, an ecosystem refers to the potential connectedness between different production functions such as inventory and planning, financials, customer relations, supply chain management (Tjahjono, Esplugues, Ares, \& Pelaez, 2017), and manufacturing execution;

- Cyber-physical systems (CPS): refers to an Industry 4.0-enabled manufacturing environment that offers real-time data collection, analysis, and transparency across every aspect of a manufacturing operation.

\section{Smart factories}

Industry 4.0 and Smart factories are terms that are often used synonymously. The focus of a smart factory is in realizing flexible and rapid manufacturing, dynamic reconfiguration, and the optimization of production according to the 
changes in the business model and consumer behavior. Further, in smart factories, the manufacturing resources migrate from local databases to cloud servers.

The architecture of a smart factory is composed of four layers, namely: physical resource layer, network layer, data application layer, and terminal layer.

The physical resource layer includes all manufacturing resources involved in the entire manufacturing life cycle, included these that are needed for intelligent manufacturing.

Currently, the manufacturing equipment in a workshop has a strong specificity and a relatively narrow range of application. The consequence of this is a reduced manufacturing flexibility and reconfigurability. Instead, the modularization of manufacturing units improves the dynamic scheduling and reconfigurability of production and control.

A modular-adaptive and self-contained reconfigurable robotic island has been suggested as a way to improve the assembly capacity of the workshop. For this purpose, a distributed algorithm for reconfiguration of lattice-based modular self-reconfigurable robots has been proposed. This would drastically simplify configuration of robots through iterative approaches.

The intelligent level of a smart factory is closely related to the modular manufacturing unit. Figure 1 illustrates the necessary components required to support a modular manufacturing unit.

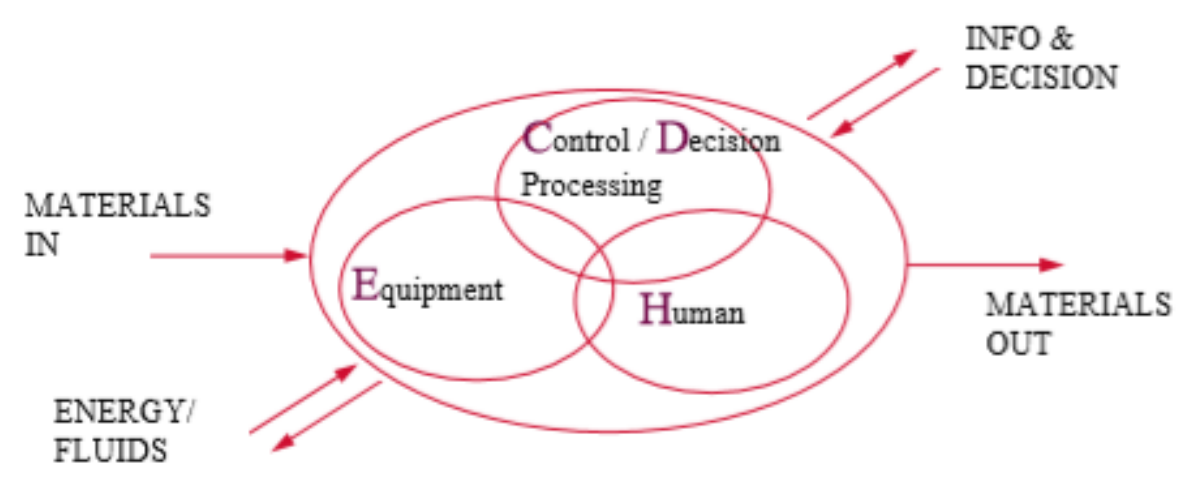

Figure 1 A modular manufacturing unit (source: McFarlane, 1998)

In a manufacturing unit, the configurability of the control system can improve the configurability of the manufacturing unit itself. Recently, multi-agent technology, knowledge modeling, and reasoning technology are being applied in the control system. Ontologies and resource descriptions based on XML have been proposed for reconfiguring production systems rapidly and automatically.

The reconfigurable production line represents a basic component of flexible manufacturing in a smart factory. It provides variability, scalability, and 
schedulability, allowing a versatile and timely response to the demands of the market.

In smart factories, wireless sensor networks (WSNs) are employed for data acquisition and logging, as well as for processes monitoring. The most common types of wireless sensor networks are Radio Frequency Identification (RFID), ZigBee, and Bluetooth. ZigBee is an open global standard for wireless technology designed to use low-power digital radio signals for personal area networks.

\section{An educational module on Industry 4.0 for higher education students}

For the 2019-2020 academic year at the Rezekne Academy of Technologies, it was decided to introduce an experimental module on Industry 4.0 to the Mechatronic curriculum of the Faculty of Engineering. The leader of the mechatronics course was persuaded that the course curriculum should be revised and reintegrated so as to provide students with new notions and competences to tackle the changes brought about by the fourth industrial revolution.

This finding also emerged as an exigent theme from NewMetro, a 36-month project supported by the EU in which the Rezekne Academy of Technologies is participating, that is aimed at developing an innovative European framework of competencies for mechatronics education.

The specific content for the module on Industry 4.0 was decided by professors and researchers coming from a wide range of backgrounds such as machine control, computer science, and process optimization. From this roundtable discussion, a module of 30 hours was designed, comprising 15 hours of theoretical notions and 15 hours of practical exercises.

The theoretical part was delineated as follows:

- 3 hours: general concepts - including the four industrial revolutions, smart factories, the value chain of an enterprise, etc.;

- 3 hours: basic concepts - such as machine to machine (or M2M) communication, big data, AI, and the IoT;

- 4 hours: industry software - for example business process management tools (or ERP), cloud computing, and cyber-physical systems;

- 3 hours: the four main features of Industry 4.0 - namely vertical networking of smart production systems, horizontal integration via a new generation of global value chain networks, through-life engineering across the entire value chain, and acceleration through exponential technologies;

- 2 hours: presentation and discussion of examples.

The exercises were prepared by researchers focusing on practical aspects of automation and robotics in modern industry, such as dynamic reconfiguration and 
the optimization of production according to the changes of business model and consumer behavior.

Lessons were designed with a view to presenting the new approach to production control, multi-agent technology, knowledge modeling, and reasoning technology. Ontologies and resource descriptions based on XML were introduced as a means to reconfigure production systems rapidly and automatically. Indeed, as previously mentioned, the reconfigurable production line is a fundamental component of flexible manufacturing in a smart factory, since it provides variability, scalability, and schedulability to enable a versatile and timely response to evolving market requirements. It was decided to then experiment the new module on a select group of students.

\section{Some considerations on an ongoing experience}

From the first lessons, it was evident that the learning program should be modified and integrated.

The concept of Industry 4.0 still lacks a shared definition (Herman, Pentek, \& Otto, 2016). It can be applied to the digitalization at any step of the value chain of an enterprise. A value chain is a business model that describes the full range of activities needed to create a product or service.

For companies that produce goods, a value chain comprises the steps that involve bringing a product from conception to distribution, and everything in between, such as the procuring of raw materials, manufacturing functions, and marketing activities.

As a consequence, Industry 4.0 encompasses the full range of activities of an enterprise necessary to create a product or service. The use of the term primarily focuses on how production shop floors currently operate, but also includes procurement and supply management (Glas \& Kleemann, 2016).

The different levels of specialization make it impossible to deal with all the variety of topics related to Industry 4.0 appropriately. The didactic materials and learning programs available on the internet confirm the difficulty of creating a complete learning program that encompasses all the aspects that are connected to Industry 4.0 and that have been highlighted in the first paragraphs of this paper.

One can find, for example, that an Industry 4.0 module should make students familiar with cloud computing and Robotic Process Automation. However, they should also understand key technologies related to IoT and industrial applications of Data Analytics. Nevertheless, experience teaches us that a course in Data Analytics requires many hours of study. The same is true for Cyber Security and Cyber-Systems from the Industrial systems perspective. Problems also arise with the use of Machine Learning and Artificial Intelligence. Finally, it is not easy teaching AI, since it covers a broad scope where there are many specializations, 
such as computer vision, natural language processing, machine learning, game playing, expert systems, decision support systems, speech recognition, intelligent information retrieval, robotics, etc. Each of these specializations require specific knowledge.

Students participating in the Industry 4.0 module had different backgrounds in computer science, and had varying levels of familiarity with computer programming. It was therefore necessary to spend some time introducing notions propaedeutic to the basic concept of AI. Nevertheless, the practical component of the AI module presented some issues. Free Industry 4.0 platforms are not available, for example, although there are some webinars available that present good examples. Accordingly, a few commercial software solutions have been analyzed and discussed with students, providing them with a basic picture of what they can find in a real enterprise.

\section{Conclusion}

This paper has reported on the introduction of a module on Industry 4.0 recently included in the mechatronics study program of the Faculty of Engineering at the Rezekne Academy of Technologies.

The training experience carried out in support of this module has been useful. In particular, it highlighted the need to introduce a module on artificial intelligence, as a prerequisite to that on Industry 4.0. This module should include, above all, the main concepts related to machine learning. In addition, attention should be paid to Bayesian inference, since numerous artificial intelligence algorithms are based on this. A background knowledge of intelligent problemsolving should also be developed, as well as strategies appropriate to the context of industrial production.

The introduction of an autonomous module on artificial intelligence would allow more attention to be paid to the integration of processes and industrial production issues.

However, it would be helpful to focus attention on concrete cases of industrial production, preparing exercises that allow students to become familiar with the main problems in the field, and the techniques for finding solutions.

Finally, during the training experience, the need emerged to begin developing an ad hoc digital training environment based on the principles of smart learning. 


\section{References}

European Commission. (2018). Pillars of the Digitising European Industry Initiative. Retrieved from https://ec.europa.eu/digital-single-market/en/pillars-digitising-european-industryinitiative

Glas, A.H., \& Kleemann, F.C. (2016). The impact of industry 4.0 on procurement and supply management: A conceptual and qualitative analysis. International Journal of Business and Management Invention, 5(6), 55-66.

Herman, M., Pentek, T., \& Otto, B. (2016). Design Principles for Industries 4.0 Scenarios. In Proceedings of the 49th Annual Hawaii International Conference on System Sciences HICSS2016, 154-160.

Hopkinson, N., Hague, R.J.M., \& Dickens, P.M. (2006). Rapid manufacturing. An Industrial Revolution for the Digital Age. Chichester, England: John Wiley \& Sons, Ltd.

Lasi, H., Fettke, P., Kemper, H.G., Feld, T., \& Hoffmann, M. (2014). Industry 4.0. Business \& information systems engineering, 6(4), 239-242.

McFarlane, D. (1998). Modular distributed manufacturing systems and the implications for integrated control. In Proceedings of IEE Colloquium on Choosing the Right Control Structure for Your Process, March 1998. Retrieved from https://pdfs.semanticscholar.org/ 0b77/6e0aa6594b4991bd60f56700ae52cd59564e.pdf

Qian, F., Zhong, W., \& Du, W. (2017). Fundamental theories and key technologies for smart and optimal manufacturing in the process industry. Engineering, 3(2), 154-160.

Qin, J., Liu, Y., \& Grosvenor, R. (2016). A categorical framework of manufacturing for industry 4.0 and beyond. Procedia Cirp, 52, 173-178.

Sousa, M.J., Cruz, R., Rocha, Á., \& Sousa, M. (2019, April). Innovation Trends for Smart Factories: A Literature Review. World Conference on Information Systems and Technologies, 689-698.

Tjahjono, B., Esplugues, C., Ares, E., \& Pelaez, G. (2017). What does industry 4.0 mean to the supply chain? Procedia Manufacturing, 13, 1175-1182. 